\title{
The location of the radial nerve in the humeral shaft between the prone and lateral decubitus positions with different elbow positions and its implications: A cadaveric study
}

\section{SITTHIPHONG SUWANNAPHISIT}

Department of Orthopedics, Faculty of Medicine, Prince of Songkla University WACHIRAKORN AONSONG

Department of Orthopedics, Faculty of Medicine, Prince of Songkla University PORAMES SUWANNO

Department of Orthopedics, Faculty of Medicine, Prince of Songkla University CHAIWAT CHUAYCHOOSAKOON ( $\square$ chaiwat.c@psu.ac.th )

Department of Orthopedics, Faculty of Medicine, Prince of Songkla University

\section{Research Article}

Keywords: microsurgery, nerve surgery, upper limb fracture

Posted Date: March 9th, 2021

DOI: https://doi.org/10.21203/rs.3.rs-176814/v1

License: (c) (i) This work is licensed under a Creative Commons Attribution 4.0 International License.

Read Full License 


\section{Abstract}

Identification of the radial nerve is important during the posterior approach to a humerus fracture. During this procedure, the patient can be placed in the prone or lateral decubitus position depending on the surgeon's preference. The distance from the radial nerve to the osseous structures will be different in each position. The purpose of this study was to identify the safety zones of the various patient and elbow flexion positions. The distances from the olecranon to the center of the radial groove and intermuscular septum and lateral epicondyle to the lateral intermuscular septum were measured using a digital Vernier caliper. The measurements were performed with the cadavers in the lateral decubitus and prone positions with different elbow flexions. The distance from where the radial nerve crossed the posterior aspect of the humerus measured from the upper part of the olecranon to the center of the radial nerve in both positions with different elbow flexion angles varied from a mean maximum distance of $130.00 \mathrm{~mm}$ with the elbow in full extension in the prone position to the shortest distance of $121.01 \mathrm{~mm}$ with elbow flexion of 120 degree in the lateral decubitus position. The mean distance of the radial nerve from the upper olecranon to the lateral intermuscular septum varied from $107.13 \mathrm{~mm}$ to $102.22 \mathrm{~mm}$. The distance from the lateral epicondyle to the lateral edge of the radial nerve varied from $119.92 \mathrm{~mm}$ to $125.38 \mathrm{~mm}$. There was very little change in the measurements and no important different distances of radial nerve location until the elbow was flexed to 120 degrees, which was not significant as this flexion is rarely used.

\section{Introduction}

Surgical intervention for a humerus fracture is common, with the posterior approach mostly preferred for fractures of the mid- to distal humerus. However, one study reported primary palsy of the radial nerve after humeral fracture repairs in $11.8 \%$ of the cases ${ }^{1}$. The incidence of iatrogenic injury to the radial nerve has been reported as $6 \%^{2}$. Injury to the radial nerve resulting in radial neuropathy or radial nerve palsy leads to wrist drop with a poor outcome ${ }^{3}$. To decrease the incidence of radial nerve palsy, identification of the exact location of the radial nerve in relation to the osseous structures is essential when preparing a posterior approach to the humerus fracture.

Various studies have examined the location of the radial nerve in relation to the common anatomical landmarks, the olecranon fossa ${ }^{3,4}$, the intersection of the long lateral head of the triceps and triceps aponeurosis ${ }^{5,6}$, and four fingerbreadths from the lateral epicondyle ${ }^{7}$. All of these studies, however, evaluated the radial nerve in only one position, which does not accurately reflect the real clinical situation in which the patient can be placed in the prone, lateral decubitus or supine positions, depending on surgeon preference, and the distance from the radial nerve to the osseous structures will be different in different positions.

To date, there have been no studies investigating the distance from the radial nerve to the important landmarks in these common surgical positions, the lateral decubitus and prone positions, with the elbow flexed at different angles. Hence, the purpose of this study was to identify the safety zones of the various patient and elbow flexion positions, to help reduce the risk of radial nerve injuries. 


\section{Methods}

Ten fresh-frozen cadavers (8 males and 2 females) from the Faculty of Science, Prince of Songkla University, were acquired for this study. The study was carried out in accordance with the guidelines and local regulations. Approval from the research and development office from the local Prince of Songkla University was granted for this experimental protocol. The donors did not have to sign a statement about this specific study but they did express their consent to anonymously give part of their body to science for ethically approved experiments. The mean age at death was $74.10 \pm 5.74$ years, and no specimens showed evidence of arm surgery. There were no significant anatomical variations and no evidence of previous traumatic upper extremity injuries in any of the cadaveric arms and elbows.

The upper arms of all cadavers were dissected and measured using a standardized protocol by a single experienced surgeon using a triceps-splitting approach. The skin and subcutaneous tissues were dissected starting with a midline incision from the posterior acromion to the olecranon. The measurements were made using a digital Vernier caliper with a precision of $0.01 \mathrm{~mm}$ (Insize Co., Ltd., Suzhou New District, China). The upper part of the olecranon and the radial nerve in the spiral groove and intermuscular septum where the radial nerve passes from the posterior to the lateral part of the arm were identified. The upper part of the olecranon was marked with K-wire as the anatomical landmark for the measurements. The distances from the upper olecranon to the radial nerve were measured with the cadaver in the prone position and elbow flexions of 0, 30, 60, 90 and 120 degrees (B1, B2, B3, B4 and B5, respectively, in Figure 1). Then the point where the radial nerve passed laterally to the intermuscular septum was identified, and the distances from the upper olecranon to the radial nerve in the lateral intermuscular septum were measured using a digital Vernier caliper with elbow flexions of $0,30,60,90$ and 120 degrees (C1, C2, C3, C4 and C5, respectively, in Figure 1). Then the distance from the lateral epicondyle to the lateral muscular septum was measured in elbow flexion positions of $0,30,60,90$ and 120 degrees (D1, D2, D3, D4 and D5, respectively). Then the cadaver was altered to the lateral decubitus position and measurements made of the distances from the upper olecranon to the center of the radial nerve in the radial groove (E1, E2, E3, E4 and E5) and the lateral intermuscular septum from the upper olecranon in different elbow positions again (F1, F2, F3, F4 and F5) and the lateral epicondyle to the lateral muscular septum $(\mathrm{G} 1, \mathrm{G} 2, \mathrm{G} 3, \mathrm{G} 4, \mathrm{G} 5)$. The measurements of each of these distances are shown in Figure 2. To decrease potential measurement bias, the distances were measured three times by the two researchers and the mean $\pm S D$ s calculated for each measurement. Statistical analysis was performed with the R program and epical package (Version 3.4.3). Differences between distances were compared using paired t-test. A $p$-value of 0.05 was considered significant due to multiple comparisons.

\section{Results}

The humeral length averaged $28.87 \mathrm{~cm}( \pm 2.71 \mathrm{~cm}$, range 24.50 to $32.60 \mathrm{~cm})$. The mean distances from the upper part of the olecranon to the radial nerve in the radial groove in different elbow flexion angles in the prone and lateral decubitus positions are summarized in Table 1. The mean distances from the upper part of the olecranon to the radial nerve in the lateral intermuscular septum in different elbow flexion 
angles in the prone and lateral decubitus positions are summarized in Table 2. The mean distances from the lateral epicondyle to the radial nerve in the lateral intermuscular septum in different elbow flexion angles in the prone and lateral decubitus positions are summarized in Table 3. From the upper part of the olecranon to the central posterior point where the radial nerve crosses the humerus, the distances were significantly lower with increasing elbow flexion angles, as shown in Figure 3. There was excellent intraobserver correlation between the two orthopedists, with correlation coefficients between 0.77 and 0.99 .

The important finding in this study was that the different distances from where the radial nerve crossed the posterior aspect of the humerus measured from the upper part of the olecranon to the center of the radial nerve in both positions with different elbow flexion angles varied from a mean maximum distance $130.00 \mathrm{~mm}$ with the elbow in full extension in the prone position to the shortest distance of $121.01 \mathrm{~mm}$ with elbow flexion of 120 degrees in the lateral decubitus position. For the lateral intermuscular septum point, the mean distance to the radial nerve varied from $102.22 \mathrm{~mm}$ to $107.13 \mathrm{~mm}$. The distance from the lateral epicondyle to the lateral edge of the radial nerve ranged from $119.92 \mathrm{~mm}$ to $125.38 \mathrm{~mm}$.

There was very little change in the measurements until the elbow was flexed to 120 degrees, a position that is rarely used with a posterior approach to the elbow. When limiting ROM to 0 to 90 degrees of elbow flexion the variation was less than $3 \mathrm{~mm}$ and not significant.

\section{Discussion}

This study describes the radial nerve anatomy at the posterior aspect of the humeral shaft in two different positions, the prone position and the lateral decubitus position, with various elbow angles. The distance of the nerve to the upper olecranon fossa at the center of the humeral shaft to the lateral edge at the intermuscular septum level in both positions decreased with increasing elbow flexion angles.

Previous anatomic studies have measured the distance from the radial nerve to various landmarks. Artico $\mathrm{M}$ et al. did a cadaveric study with the bodies placed in the lateral decubitus position with the arms adducted and the forearms completely supinated with 45 degrees flexion of the elbow joint ${ }^{8}$. The mean distances between the entry point of the nerve in the lateral intermuscular septum and the medial and lateral epicondyles were $133 \pm 14$ and $110 \pm 23 \mathrm{~mm}$, respectively. Carlen et al. reported that the radial nerve was located $10.9 \pm 1.5 \mathrm{~cm}$ proximal to the lateral epicondyle at the lateral border of the humeral shaft ${ }^{9}$. A recent study by Jain et al. investigated the location of the radial nerve in relation to the medial and lateral epicondyles, and found the mean distance from the lateral epicondyle to the entry of the radial nerve into the spiral groove was $11.34 \pm 0.41 \mathrm{~cm}^{10}$. A study by Hackl on 100 cadavers reported the average distances from the proximal edge of the olecranon fossa to the radial nerve at the center and lateral edge of the posterior aspect of the humeral shaft were $12.7 \pm 1.6 \mathrm{~cm}$ and $10.6 \pm 1.3 \mathrm{~cm}^{4}$, respectively. However, these studies were performed with the elbow in a static position, and thus the findings do not correspond to the true clinical situation. 
In fact, the radial nerve can vary in position during upper-extremity motions. One study ${ }^{11}$ found that shoulder abduction from 30 degrees to 110 degrees required $4 \mathrm{~mm}$ of radial nerve excursion at the elbow. The greatest radial nerve migration was $11.4 \mathrm{~mm}$ with shoulder abduction of 110 degrees and elbow flexion of 90 degrees ${ }^{11}$. However, this study investigated radial nerve excursion at a point approximately 4-6 $\mathrm{cm}$ proximal to the lateral epicondyle, and the findings are not relevant in the situation of a midshaft of humerus fracture. Another study ${ }^{12}$ suggested that radial nerve excursion can be improved with elbow flexion and lateral intermuscular septum release by approximately 3 times. Our current study aimed to provide accurate information concerning the points of entry and exit of the radial nerve around the elbow which can be applied in the case of a humerus fracture. We found that there was a little change of nerve location between the two positions in different elbow flexions from 0 to 90 degrees, except when the flexion exceeded 120-degrees, when the distance was $\pm 3 \mathrm{~mm}$ from the mid-point of the humerus to the lateral intermuscular septum. The reason to explain a little change of radial nerve distance due to its anatomic that the course of radial nerve run posterior to spiral groove, exits to anterior via lateral intermuscular septum with usually course tethering the distal part of radial nerve of arm, consequently minimal dynamic change.

In terms of clinical implications, our findings show that the posterior approach in either the prone or lateral decubitus position can be used in diaphyseal middle-third to distal-third procedures ${ }^{13,14}$. Our study identifies the safe zones for the radial nerve in each position. The surgeon can use our findings concerning the safe zone in different elbow flexion angles in their preferred position. In the case of a distal humerus fracture with intact olecranon fossa or a simple fracture of the distal humerus according to the $\mathrm{AO}$ classifications (AO-OTA 13 type $\mathrm{A}, \mathrm{B}$ and $\mathrm{C} 1)^{15}$, we found that the olecranon fossa was a reliable landmark to estimate the location of the radial nerve when using the posterior approach.

The study had potential limitation. The length of the nerve in the lateral intermuscular bundle may have been changed by dissecting the triceps muscle, although we attempted to minimize this possible problem by dissecting only the triceps and identifying and leaving intact the radial nerve.

There were no significant differences in the measurements and no important different distances of radial nerve location until the elbow was flexed to greater than 120 degrees, which was not significant as this flexion is rarely used. Understanding the distance of the radial nerve in both lateral decubitus and prone positions from these common landmarks in the various common operative positions is helpful in avoiding iatrogenic radial nerve injury during a surgical approach to the mid- to distal third of the shaft of the humerus.

\section{Declarations}

\section{Compliance with ethical standards}

Conflicts of interest: None 


\title{
Disclosures
}

\begin{abstract}
All authors - SITTHIPHONG SUWANNAPHISIT, WACHIRAKORN AONSONG, PORAMES SUWANNO, and CHAIWAT CHUAYCHOOSAKOON - declare they have no funding or commercial associations that might pose a conflict of interest in connection with the submitted article.

\section{Acknowledgements}

The authors sincerely thank Chittipong Tipbunjong (Head of the Anatomy Department) and Kosol Puriwattanakle and her assistants in the Anatomy Department, Faculty of Science for arranging to supply the cadavers; Nannapat Pruhetkaew of the Epidemiology Unit, Faculty of Medicine for providing statistical support; Piya Chavalparit for their assistance with the demonstration drawing; and Dave Patterson for his editing support.
\end{abstract}

\section{References}

1. Shao YC, Harwood P, Grotz MRW, Limb D, Giannoudis PV. Radial nerve palsy associated with fractures of the shaft of the humerus: A systematic review. J Bone Joint Surg Br. 2005 ;87B(12):1647-52.

2. Schwab TR, Stillhard PF, Schibli S, Furrer M, Sommer C. Radial nerve palsy in humeral shaft fractures with internal fixation: analysis of management and outcome. Eur J Trauma Emerg Surg. 2018 ;44(2):235-43.

3. Kamineni S, Ankem H, Patten DK. Anatomic relationship of the radial nerve to the elbow joint: Clinical implications of safe pin placement. Clin Anat. $2009 ; 22(6): 684-8$.

4. Hackl M, Damerow D, Leschinger T, Scaal M, Müller LP, Wegmann K. Radial nerve location at the posterior aspect of the humerus: an anatomic study of 100 specimens. Arch Orthop Trauma Surg. $2015 ; 135(11): 1527-32$.

5. Seigerman DA, Choung EW, Yoon RS, Lu M, Frank MA, Gaines LRJ, et al. Identification of the Radial Nerve During the Posterior Approach to the Humerus: A Cadaveric Study. Journal of Orthopaedic Trauma. $2012 ; 26(4): 226-228$

6. Chaudhry T, Noor S, Maher B, Bridger J. The surgical anatomy of the radial nerve and the triceps aponeurosis. Clin Anat. $2010 ; 23(2): 222-6$

7. Simone JP, Streubel PN, Sánchez-Sotelo J, Steinmann SP, Adams JE. Fingerbreadths Rule in Determining the Safe Zone of the Radial Nerve and Posterior Interosseous Nerve for a Lateral Elbow Approach: An Anatomic Study. J Am Acad Orthop Surg. 2019 ;3(2):6.

8. Artico M, Telera S, Tiengo C, Stecco C, Macchi V, Porzionato A, et al. Surgical anatomy of the radial nerve at the elbow. Surg Radiol Anat. $2009 ; 31(2): 101-6$.

9. Carlan D, Pratt J, Patterson JM, Weiland AJ, Boyer MI, Gelberman RH. The radial nerve in the brachium: an anatomic study in human cadavers. J Hand Surg Am. 2007 ;32(8):1177-82. 
10. Jain RK, Champawat VS, Mandlecha P. Danger zone of radial nerve in Indian population - A cadaveric study. J Clin Orthop Trauma. $2019 ; 10(3): 531-4$.

11. Wright TW, Glowczewskie F Jr, Cowin D, Wheeler DL. Radial nerve excursion and strain at the elbow and wrist associated with upper-extremity motion. J Hand Surg Am. 2005 Sep;30(5):990-6.

12. Chen WA, Luo TD, Wigton MD, Li Z. Anatomical Factors Contributing to Radial Nerve Excursion at the Brachium: A Cadaveric Study. J Hand Surg Am. 2018 Mar;43(3):288.e1-288.

13. Stanley Hoppenfeld, Piet De Boer, Richard Buckley, Hugh A. Thomas. Surgical exposures in orthopaedics. The anatomic approach. 4th ed. Lippincott Williams \& Wilkins; 2009.

14. Maresca A, Fantasia R, Cianforlini M, Giampaolini N, Cerbasi S, Pascarella R. Distal-third diaphyseal fractures of the humerus: choice of approach and surgical treatment. Musculoskelet Surg. 2016 ;100(S1):97-104.

15. Müller M.E., Koch P., Nazarian S., Schatzker J. Principles of the Classification of Fractures. In: The Comprehensive Classification of Fractures of Long Bones. Springer, Berlin, Heidelberg; 1990.

\section{Tables}

Table 1: Distances from the upper olecranon to the center of the radial nerve in posterior shaft of

the humerus 


\begin{tabular}{|c|c|c|c|c|c|c|}
\hline \multirow[b]{2}{*}{$\begin{array}{l}\text { iw } \\
\text { on } \\
\text { e }\end{array}$} & \multicolumn{2}{|c|}{ Prone position (mm) } & \multicolumn{2}{|c|}{ Lateral decubitus (mm) } & \multirow[b]{2}{*}{$\begin{array}{l}\text { Mean } \\
\text { difference } \\
(95 \% \text { CI })\end{array}$} & \multirow[b]{2}{*}{$\begin{array}{l}\mathrm{P} \\
\text { value }\end{array}$} \\
\hline & Mean \pm SD & Minimum & Mean \pm SD & Minimum & & \\
\hline ees & $130.00 \pm 2.07(\mathrm{~B} 1)$ & 113.70 & $128.00 \pm 1.89(\mathrm{E} 1)$ & 114.90 & $\begin{array}{l}1.69 \\
(-1.99- \\
5.35) \\
\end{array}$ & 0.35 \\
\hline :es & $128.10 \pm 2.81(\mathrm{~B} 2)$ & 114.95 & $127.16 \pm 2.70(\mathrm{E} 2)$ & 112.67 & $\begin{array}{l}0.63 \\
(-2.47- \\
3.72) \\
\end{array}$ & 0.68 \\
\hline əes & $127.98 \pm 2.81(\mathrm{~B} 3)$ & 115.18 & $126.72 \pm 2.94(\mathrm{E} 3)$ & 104.33 & $\begin{array}{l}0.95 \\
(-2.55- \\
4.45) \\
\end{array}$ & 0.58 \\
\hline :es & $128.12 \pm 2.91(\mathrm{~B} 4)$ & 111.66 & $125.75 \pm 2.99(\mathrm{E} 4)$ & 105.67 & $\begin{array}{l}2.06 \\
(-1.07- \\
5.18) \\
\end{array}$ & 0.19 \\
\hline $\begin{array}{l}\text { ) } \\
\text { əes }\end{array}$ & $123.12 \pm 2.91(\mathrm{~B} 5)$ & 110.14 & $121.01 \pm 3.34(\mathrm{E} 5)$ & 94.69 & $\begin{array}{l}1.80 \\
(-3.48- \\
7.06) \\
\end{array}$ & 0.449 \\
\hline
\end{tabular}

Table 2: Distances from the upper olecranon to the lateral intermuscular septum

Prone position $(\mathrm{mm}) \quad$ Lateral decubitus $(\mathrm{mm})$

\begin{tabular}{|c|c|c|c|c|c|c|}
\hline on & Mean \pm SD & Minimum & Mean \pm SD & Minimum & $\begin{array}{l}\text { Mean } \\
\text { difference } \\
(95 \% \text { CI })\end{array}$ & $\begin{array}{l}\mathrm{P} \\
\text { value }\end{array}$ \\
\hline rees & $106.00 \pm 1.81(\mathrm{C} 1)$ & 90.50 & $105.92 \pm 1.81(\mathrm{~F} 1)$ & 92.43 & $\begin{array}{c}1.21 \\
(-4.02- \\
1.60)\end{array}$ & 0.38 \\
\hline & $107.13 \pm 2.56(\mathrm{C} 2)$ & 91.31 & $107.05 \pm 2.56(\mathrm{~F} 2)$ & 93.95 & $\begin{array}{c}1.76 \\
(0.04- \\
3.48) \\
\end{array}$ & 0.04 \\
\hline $\begin{array}{l}1 \\
\text { zes }\end{array}$ & $103.79 \pm 2.49(\mathrm{C} 3)$ & 88.74 & $103.71 \pm 2.49(\mathrm{~F} 3)$ & 91.28 & $\begin{array}{c}3.03 \\
(-5.69- \\
0.37) \\
\end{array}$ & 0.02 \\
\hline $\begin{array}{l}1 \\
\text { 3es }\end{array}$ & $105.78 \pm 2.47(\mathrm{C} 4)$ & 91.4 & $105.69 \pm 2.47(\mathrm{~F} 4)$ & 92.25 & $\begin{array}{c}0.58 \\
(-2.43- \\
3.59) \\
\end{array}$ & 0.69 \\
\hline $\begin{array}{l}0 \\
\text { zes }\end{array}$ & $102.30 \pm 2.83(\mathrm{C} 5)$ & 86.10 & $102.22 \pm 2.83(\mathrm{~F} 5)$ & 86.10 & $\begin{array}{c}1.85 \\
(-0.13- \\
3.83)\end{array}$ & 0.06 \\
\hline
\end{tabular}


Table 3: Distances from the lateral epicondyle to the lateral intermuscular septum Prone position $(\mathrm{mm}) \quad$ Lateral decubitus $(\mathrm{mm})$

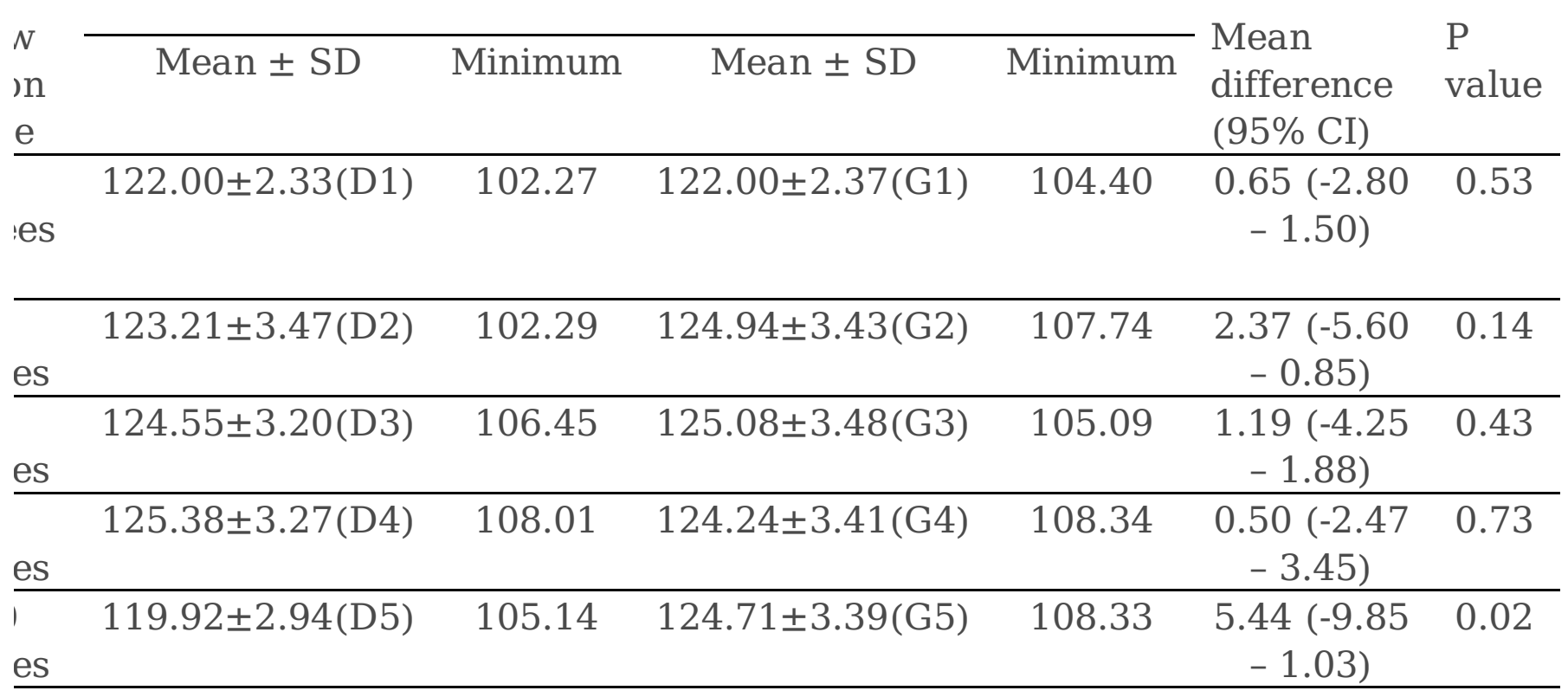

\section{Figures}

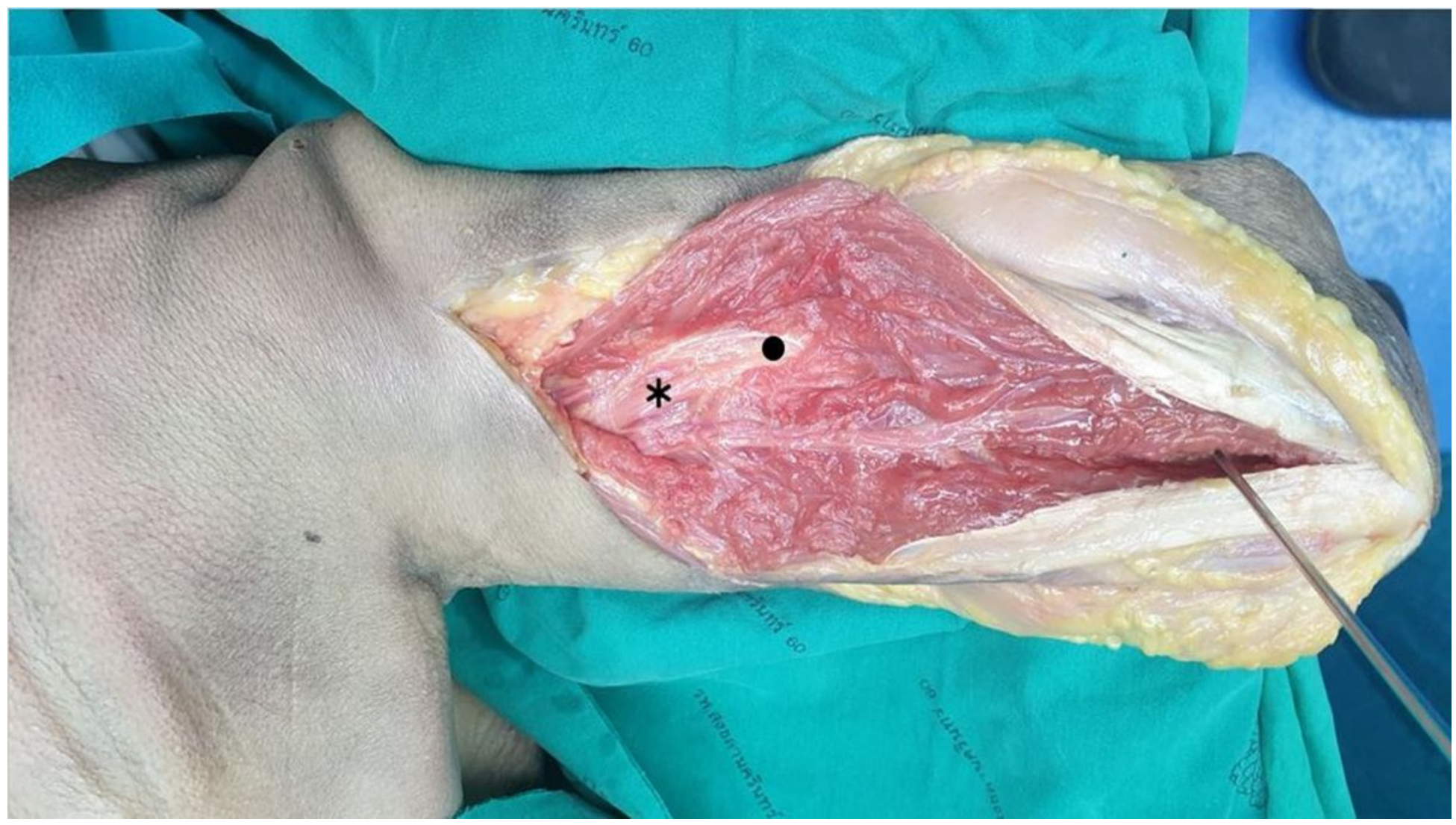


Illustrating the posterior approach via the triceps-split technique. * Center of the radial nerve in the posterior shaft of humerus $•$ Radial nerve at the lateral intermuscular septum

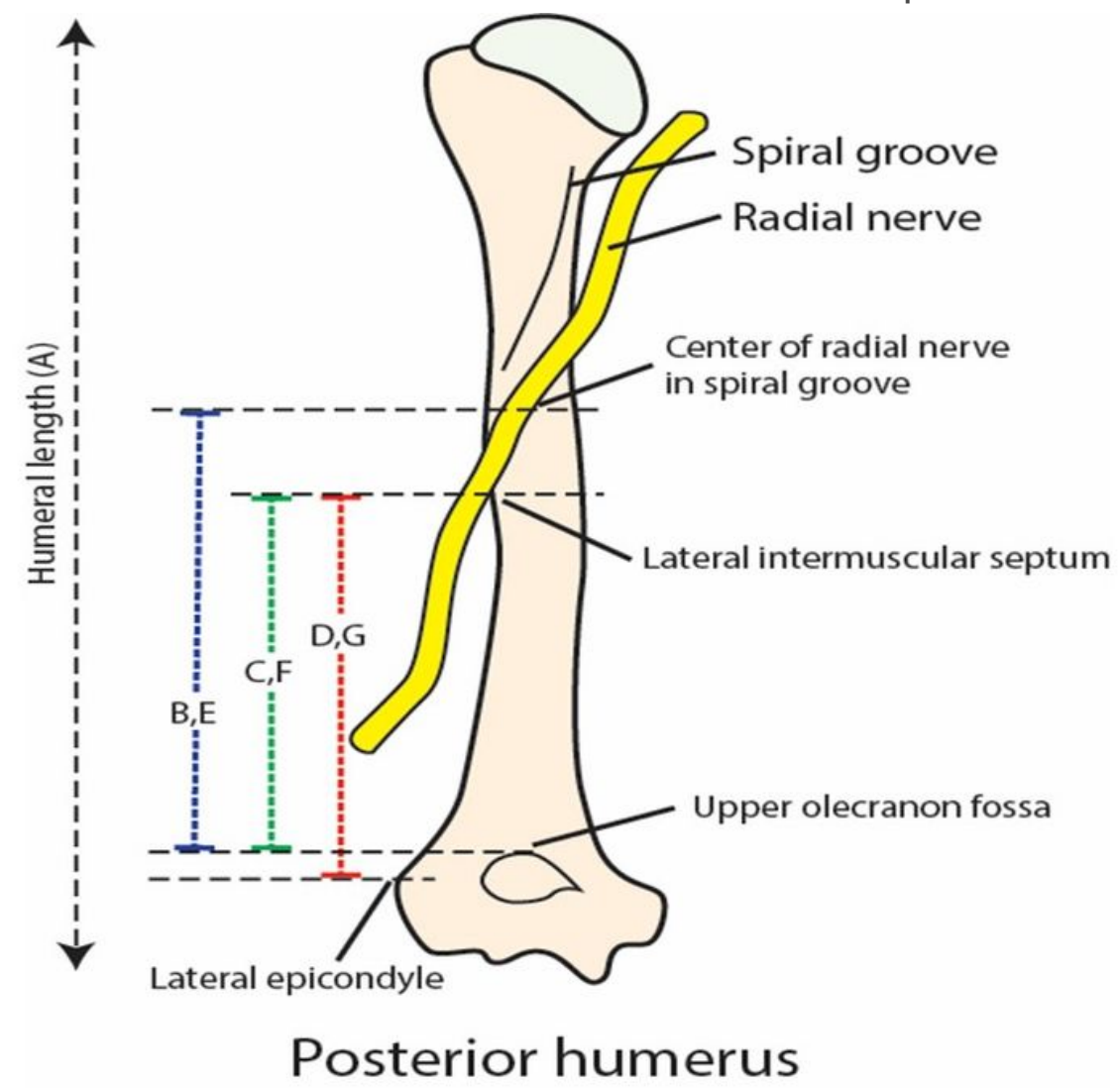

\section{Figure 2}

Illustrating the text references text for each distance A: Humerus length: posterior acromion to tip of olecranon B: Upper olecranon fossa to radial groove in prone position C: Upper olecranon fossa to lateral intermuscular septum in prone position D: Lateral epicondyle to lateral intermuscular septum in prone position E: Upper olecranon fossa to radial groove in lateral decubitus position F: Upper olecranon fossa to lateral intermuscular septum in lateral decubitus position $\mathrm{G}$ : Lateral epicondyle to lateral intermuscular septum in lateral decubitus position 


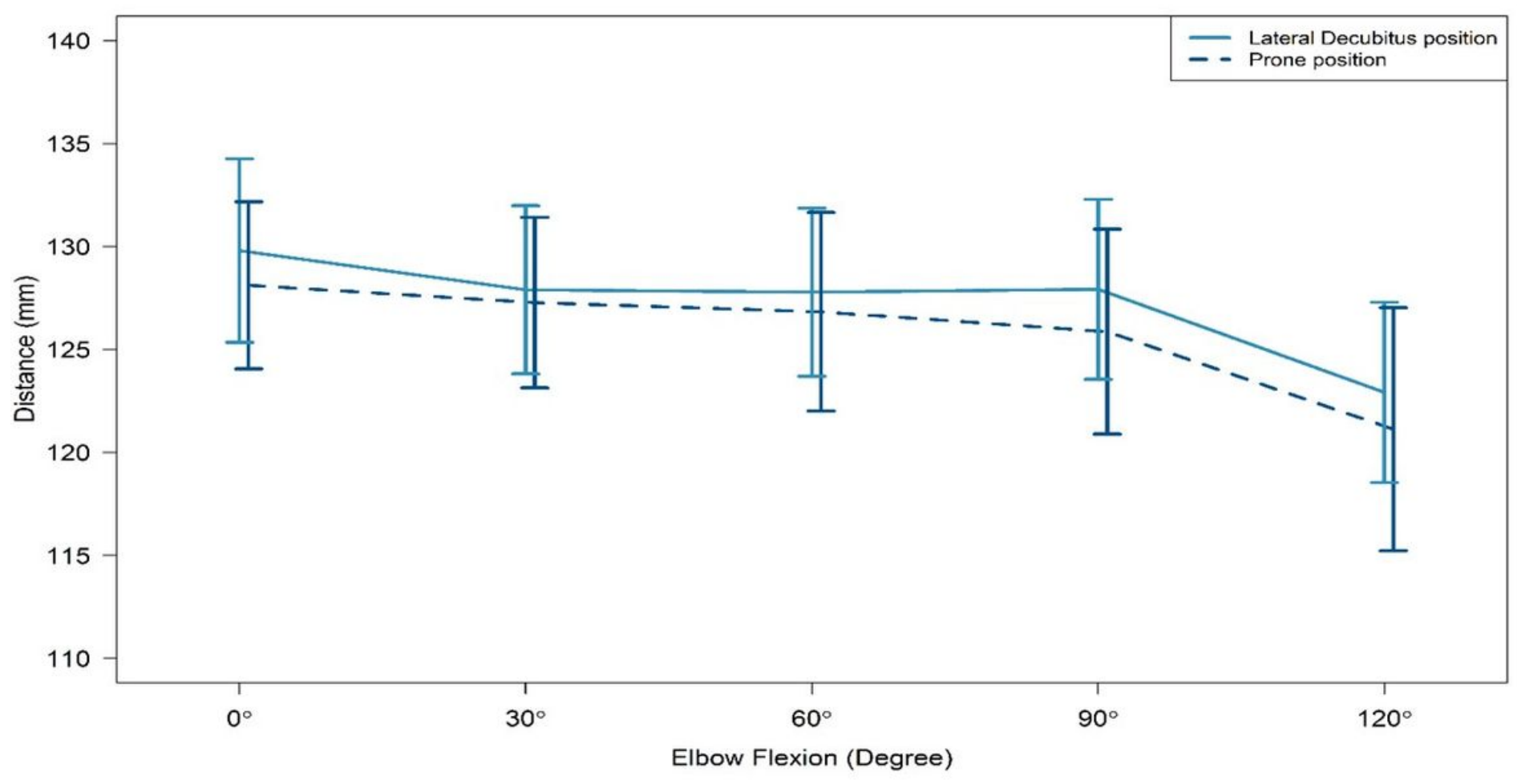

Figure 3

A line graph showing the distance from the upper part of the olecranon to the center of the radial nerve in each position 